\title{
Patients with cranial dural arteriovenous fistulas may benefit from expanded hypercoagulability and cancer screening
}

\author{
${ }^{*}$ Sean P. Polster, MD, ${ }^{1}$ Hussein A. Zeineddine, MD, ${ }^{1}$ Joseph Baron, MD, ${ }^{2}$ Seon-Kyu Lee, MD, PhD, ${ }^{1,3}$ \\ and Issam A. Awad, MD'
}

${ }^{1}$ Department of Surgery, Section of Neurosurgery, ${ }^{2}$ Department of Medicine, Section of Hematology and Oncology, and ${ }^{3}$ Department of Radiology, Section of Neuroradiology, University of Chicago Medicine, Chicago, Illinois

\begin{abstract}
OBJECTIVE Cranial dural arteriovenous fistulas (DAVFs) have been associated with dural sinus occlusion, and previous reports have suggested the association of hypercoagulability with some cases. But the prevalence of a hypercoagulable state has not been systematically analyzed in conjunction with laboratory markers and clinical manifestations, including history of thromboembolism or systemic malignancy. The authors hypothesize that laboratory or clinical evidence of a hypercoagulable state, including cancer, is commonly identifiable in consecutively identified patients with DAVFs, with implications for clinical management.
\end{abstract}

METHODS The retrospective cohort study included all patients older than 17 years with cranial DAVFs diagnosed at University of Chicago Medicine during a 6-year period, whose medical records and imaging results were reviewed for objective laboratory or clinical evidence of a hypercoagulable state, including malignancy. Each case was analyzed for implications on clinical management. Data were analyzed in relation to a systematic review of the literature on this association.

RESULTS Fifteen ( $88 \%$ ) of 17 cases of DAVFs had laboratory $(n=8)$ or clinical evidence of a hypercoagulable state (thromboembolism [ $n=8]$ or cancer [ $n=6]$ ). This hypercoagulability or cancer impacted clinical care in all 15 cases.

CONCLUSIONS An underlying hypercoagulable state manifested by laboratory testing or clinically, including cancer, is staggeringly common. It is important to recognize this association, along with its impact on the management of the DAVFs and systemic diseases.

https://thejns.org/doi/abs/10.3171/2017.5.JNS17788

KEY WORDS dural arteriovenous fistula; coagulation; hypercoagulable condition; cancer; oncology; vascular disorders

$\mathrm{D}$ URAL arteriovenous fistulas (DAVFs), also known as malformations or shunts, have long been believed to arise in the setting of dural sinus thrombosis and venous hypertension. $1,5,7,13,14,17,34,40$ DAVFs have also been reported in the setting of postoperative sinus manipulation, head trauma, and less frequently in the setting of meningiomas. ${ }^{4,8,12,18,30}$

Several reports have identified hypercoagulable states in patients with DAVFs, including prothrombotic genes, or acquired hypercoagulopathy associated with malignancy, pregnancy, or infection. ${ }^{23,25,30,36}$ However, the prevalence of such states could not be gleaned from case reports, and reported series often included inconsistent case selection, and variable and often limited hypercoagulability surveys. ${ }^{14,23,25,35}$ Recent evidence-based guidelines for the clinical management of DAVFs did not consider or address an association with a hypercoagulable state. ${ }^{29} \mathrm{We}$ hypothesize that hypercoagulable factors are common in

ABBREVIATIONS DAVF = dural arteriovenous fistula; DSA = digital subtraction angiography; DVT = deep vein thrombosis; MRA = MR angiography; MRV = MR venography; $P E=$ pulmonary embolism.

SUBMITTED March 31, 2017. ACCEPTED May 23, 2017.

INCLUDE WHEN CITING Published online November 17, 2017; DOI: 10.3171/2017.5.JNS17788.

* Drs. Polster and Zeineddine contributed equally to this work. 

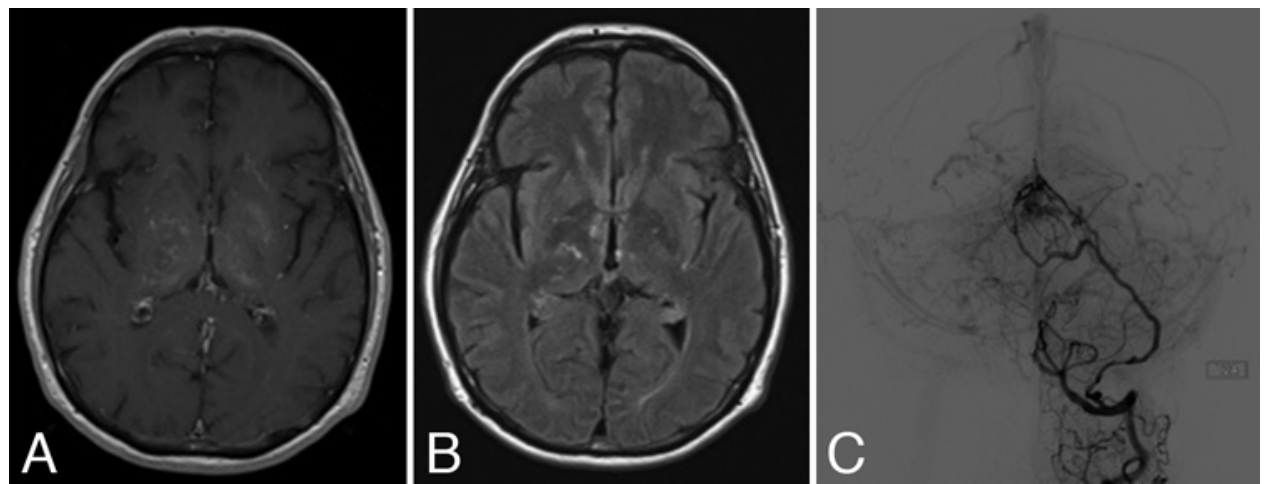

FIG. 1. Axial T1-weighted postcontrast MR image (A), axial FLAIR MR image (B), and anteroposterior projection of the left vertebral digital subtraction angiogram (C) from a 68-year-old man with a DAVF draining with retrograde Galenic leptomeningeal venous drainage, who presented with congestive venous encephalopathy including cognitive, gait, and midbrain (gaze) signs and symptoms (Case 2, Table 1). The MRI revealed prominent deep veins and FLAIR abnormalities in the deep cerebral hemisphere and midbrain from congestive venous encephalopathy. Angiography revealed a major arterial supply from the dorsal meningeal branch of the vertebral artery. The lesion was successfully obliterated with transarterial embolization. Laboratory tests identified a previously unsuspected heterozygous factor $\vee$ mutation and antiphospholipid antibody and elicited a history of lower extremity DVT. The patient is receiving lifelong therapeutic anticoagulation treatment, with no recurrent sequelae during 5 years of follow-up after verified DAVF occlusion, regression of venous encephalopathy, and complete neurological recovery.

consecutive cases of cranial DAVFs, and that they impact clinical management.

\section{Methods}

This study was approved by the local IRB, which waived the need for patient consent in this study.

\section{Patient Selection and Clinical Features}

The retrospective cohort study identified all patients ( $>$ 17 years of age) diagnosed with cranial DAVFs at our institution during a 6-year period (January 2010 to December of 2016), based on screening of management case logs, ICD-9 diagnosis code 447.0, or key word survey ("dural" and "arteriovenous") in radiology reports. The diagnosis of DAVF was confirmed by review of digital subtraction angiography (DSA) or MRI, MR angiography (MRA), and MR venography (MRV). Figure 1 shows an illustrative case. Patient demographics including age at diagnosis, sex, smoking status, and comorbidities were reviewed. Clinical and imaging features of the DAVF were noted, including referral source, symptoms at presentation, and Borden class. $^{5}$

\section{Hypercoagulability}

There was no standardized policy of screening for hypercoagulability during the period of the study. However, because of our awareness of previous case reports and reported associations, there was a low threshold of assessing for a hypercoagulable state. At the time of presenting to the neurovascular team, the patient's clinical history was assessed for any evidence of known hypercoagulability and the laboratory workup was ordered in conjunction with the clinical care of the DAVF at first visit. Clinical evidence was specifically sought from the clinical record, including any history of prior venous thromboembolic events and/or the presence of malignancy. Thromboembolic events included a history of deep vein thrombosis
(DVT), pulmonary embolism (PE), or dural sinus thrombosis at any time prior to or in conjunction with a diagnosis of DAVF. Thromboembolic events were adjudicated by confirmatory imaging evidence (lower extremity Doppler ultrasonography, CT or venous angiography, or MRI/ MRA/MRV). The medical oncology team adjudicated the cancer diagnosis.

Laboratory markers of a venous hypercoagulable state, when assessed, included the following test panel according to established clinical protocols at our institution:10,22 1) prothrombin gene mutation G20210A; 2) antiphospholipid antibodies including 1 or more of the following: lupus anticoagulant, anticardiolipin, antibeta 2 glycoprotein 1, and antiphosphatidylserine antibodies; 3) abnormal homocysteine level; 4) protein $\mathrm{C}$ deficiency; 5) protein $\mathrm{S}$ deficiency; 6) APC resistance/factor V Leiden mutation; 7) elevated factor VIII; and 8) antithrombin III.

Smoking status or history of tobacco products was also reviewed. However, smoking alone was not considered a criterion for hypercoagulability.

\section{Systematic Literature Review}

A systematic literature review was completed using the English electronic databases MEDLINE and Scopus with the word search ("dural arteriovenous fistula" OR "dural arteriovenous fistulae" OR "dural arteriovenous malformation") AND ("thrombophilia" OR "coagulation" OR "hypercoagulability"). We included all case series with more than a single case report. Papers addressing spinal DAVFs exclusively and pediatric series were excluded. Cranial cases were considered separately, whenever possible, in series that included both cranial and spinal DAVFs.

\section{Results}

\section{Patient Characteristics}

Seventeen consecutive adult patients (age $>17$ years) 
TABLE 1. Patient and DAVF characteristics, clinical evidence of thromboembolism or cancer, and laboratory evidence of hypercoagulable state

\begin{tabular}{|c|c|c|c|c|c|c|c|c|}
\hline $\begin{array}{l}\text { Case } \\
\text { No. }\end{array}$ & $\begin{array}{l}\text { Age at } \\
\text { Presentation } \\
\text { (yrs), Sex }\end{array}$ & $\begin{array}{l}\text { Presentation } \\
\text { (referring service) }\end{array}$ & $\begin{array}{c}\text { Borden } \\
\text { Classification }\end{array}$ & $\begin{array}{l}\text { History } \\
\text { of } \\
\text { Smoking }\end{array}$ & $\begin{array}{l}\text { Laboratory Evidence of } \\
\text { Hypercoagulability }\end{array}$ & $\begin{array}{c}\text { Clinical } \\
\text { Thromboembolism }\end{array}$ & Malignancy & $\begin{array}{l}\text { Factors } \\
\text { Positive }\end{array}$ \\
\hline 1 & $78, \mathrm{M}$ & VCE (ED) & ॥ & Yes & Yes (elevated homocysteine) & No & No & 1 \\
\hline 2 & $68, \mathrm{M}$ & VCE (neurology) & II & Yes & $\begin{array}{l}\text { Yes (heterozygous factor V, } \\
\text { antiphospholipid antibody) }\end{array}$ & Yes $^{*}$ & No & 3 \\
\hline 3 & $41, \mathrm{~F}$ & VCE (neurology) & II & No & Yes (protein S deficiency) & Yes $^{*}$ & No & 2 \\
\hline 4 & $80, \mathrm{M}$ & VCE (oncology) & III & Yes & Lab tests not done & No & Lung cancer & 1 \\
\hline 5 & $64, \mathrm{M}$ & $\begin{array}{r}\text { Cranial neuropathy } \\
\text { (ophthalmology) }\end{array}$ & 1 & No & Lab tests not done & No & No & 0 \\
\hline 6 & $51, \mathrm{~F}$ & $\begin{array}{l}\text { Pulsatile tinnitus } \\
\text { (primary care) }\end{array}$ & II & No & No & Yes $^{*}$ & No & 1 \\
\hline 7 & $43, M$ & $\mathrm{ICH}(\mathrm{ED})$ & III & Yes & No & Yes $^{*}$ & Thyroid cancer & 2 \\
\hline 8 & $58, \mathrm{M}$ & VCE (ED) & $\|$ & Yes & Lab tests not done & Yest & $\begin{array}{l}\text { Nasopharyn- } \\
\text { geal cancer }\end{array}$ & 2 \\
\hline 9 & $54, \mathrm{~F}$ & VCE (neurology) & $\begin{array}{l}\text { II, III (2 differ- } \\
\text { ent DAVFs) }\end{array}$ & No & Yes (elevated factor VIII) & Yes $^{*} \dagger$ & No & 3 \\
\hline 10 & $70, \mathrm{M}$ & VCE (neurosurgery) & $\begin{array}{l}\text { I, II (2 different } \\
\text { DAVFs) }\end{array}$ & Yes & $\begin{array}{l}\text { Yes (activated protein } \mathrm{C} \\
\text { resistance) }\end{array}$ & Yest & No & 2 \\
\hline 11 & $67, \mathrm{M}$ & $\mathrm{ICH}(\mathrm{ED})$ & II & Yes & Lab tests not done & No & No & 0 \\
\hline 12 & $63, \mathrm{M}$ & $\mathrm{ICH}$ (neurology) & III & Yes & Lab tests not done & No & ALL & 1 \\
\hline 13 & $76, \mathrm{M}$ & VCE (neurology) & III & Yes & Lab tests not done & No & Colon cancer & 1 \\
\hline 14 & $65, \mathrm{~F}$ & $\begin{array}{l}\text { Pulsatile tinnitus } \\
\text { (primary care) }\end{array}$ & 1 & Yes & $\begin{array}{l}\text { Yes (antiphospholipid } \\
\text { antibody) }\end{array}$ & No & Breast cancer & 2 \\
\hline 15 & $47, \mathrm{M}$ & $\mathrm{ICH}$ (neurology) & II & No & Lab tests not done & Yes $^{*}$ & No & 1 \\
\hline 16 & $75, \mathrm{~F}$ & $\begin{array}{l}\text { Pulsatile tinnitus } \\
\text { (primary care) }\end{array}$ & I & Yes & $\begin{array}{l}\text { Yes (prothrombin G20210A } \\
\text { mutation, anticardiolipin } \\
\text { antibody) }\end{array}$ & No & No & 2 \\
\hline 17 & $62, \mathrm{~F}$ & $\begin{array}{l}\text { Cranial neuropathy } \\
\text { (neurology) }\end{array}$ & I & Yes & Yes (protein S deficiency) & No & No & 1 \\
\hline
\end{tabular}

$\mathrm{ALL}$ = acute lymphoblastic leukemia; $\mathrm{ED}$ = emergency department; $\mathrm{ICH}$ = intracerebral hemorrhage; $\mathrm{VCE}$ = nonhemorrhagic venous congestive encephalopathy.

* History of DVT or PE.

$\dagger$ History of acute sinus thrombosis.

$\ddagger$ Meningioma occluding venous sinus involved in DAVF.

were identified to have cranial DAVFs and were included in this study. The institution's Neurovascular Surgery and Neurointerventional Programs managed these cases. The diagnosis of DAVF was established or confirmed by DSA in 16 cases, and by MRI/MRA/MRV in 1 case that was managed palliatively because of associated malignancy.

The mean patient age at the time of diagnosis was 62 years (range $33-80$ years). Eleven patients (65\%) were male and 6 patients $(35 \%)$ were female. Four patients presented with intracerebral hemorrhage and 8 had nonhemorrhagic cerebral venous congestive encephalopathy, and all 12 of these patients harbored retrograde leptomeningeal venous drainage (Borden Class II or III). Five patients had minor symptoms ( 2 with cranial neuropathy, 3 with pulsatile tinnitus), and all but 1 had a Borden Class I lesion without leptomeningeal venous drainage. Twelve (71\%) of the 17 patients had a history of smoking. None of the patients had a noted history of significant head trauma or pregnancy in the year preceding DAVF diagnosis.

\section{Prevalence of Hypercoagulability}

Fifteen (88\%) of the 17 patients had an associated hypercoagulable state based on clinical or laboratory criteria (Table 1). Eight patients (47\%) had evidence of clinical thromboembolism (5 had prior DVT or PE, 2 had prior acute dural sinus thrombosis, and 1 had both a prior DVT and sinus thrombosis). Six patients (35\%) had cancer, 5 prior to diagnosis of a DAVF, and 1 in whom malignancy was discovered soon after. Three patients were screened for cancer ( 2 with a PET scan and 1 with CT of the chest/ abdomen/pelvis with contrast). Of those 3 patients, 1 was found to harbor colon cancer. Of 10 patients who underwent laboratory workup of hypercoagulability, $8(80 \%)$ tested positive for a hypercoagulable marker ( 8 of $17,47 \%$ in the whole series). Laboratory hypercoagulability tests were not available in 7 patients (testing was not pursued in 4 cases as they had other clinical evidence of hypercoagulability including cancer, and 3 either refused test- 
Patients with DAVFs require expanded hypercoagulability workup

TABLE 2. Prevalence of laboratory and clinical markers of hypercoagulability in cranial DAVFs in reported series and the current study

\begin{tabular}{lccccc}
\hline \multicolumn{1}{c}{ Study } & $\begin{array}{c}\text { No. of Patients w/ } \\
\text { Cranial DAVFs }\end{array}$ & $\begin{array}{c}\text { Patients w/ } \\
\text { Hypercoagulability Marker** }\end{array}$ & $\begin{array}{c}\text { Lab/Clinical } \\
\text { Thromboembolisms }\end{array}$ & $\begin{array}{c}\text { Prevalence of } \\
\text { Hypercoagulability* }\end{array}$ & $\begin{array}{c}\text { Prevalence of Lab/Clinical } \\
\text { Thromboembolism }\end{array}$ \\
\hline Kraus et al., 1998, 2000, 2002 & 23 & 6 & $6 / 3$ & $26 \%$ & $26 \% / 13 \%$ \\
\hline van Dijk et al., 2007† & $40 \ddagger$ & Unknown & $4 / 6$ & Unknown & $10 \% / 15 \%$ \\
\hline Izumi et al., 2007 & 18 & 17 & $16 / 8$ & $94 \%$ & $89 \% / 44 \%$ \\
\hline Gerlach et al., 2008† & 25 & Unknown & $10 / 7$ & Unknown & $40 \% / 28 \%$ \\
\hline Current study§ & 17 & 15 & $8 / 8 / 6$ & $88 \%$ & $47 \% / 47 \% / 35 \%$ \\
\hline
\end{tabular}

* Number and prevalence of cases with laboratory and/or clinical history of thrombotic events. Hypercoagulability testing varied and often included fewer tests or clinical factors than considered in the current study. Cancer association was only sought in the current study.

$\dagger$ Prevalence of total number of patients with hypercoagulability could not be calculated.

$\ddagger$ Authors did not separate patients into cranial and spinal DAVFs, but we opted to include the study due to its large sample size.

$\S$ Laboratory/clinical thromboembolism/cancer.

ing or were lost to follow-up). Eight of the 17 patients in this series had more than 1 clinical or laboratory marker of hypercoagulability at the time of DAVF diagnosis, including the 2 cases with 2 distinct DAVFs. Eleven (73\%) of the 15 patients with a hypercoagulable state were smokers, as well as 1 of the 2 without a hypercoagulable state.

Clinical care was influenced in all 15 cases in which a hypercoagulable state was identified. In each instance, there were special considerations on the timing and modality of DAVF treatment given the associated hypercoagulability or malignancy. In 10 cases, therapeutic anticoagulation was deployed for hypercoagulability after embolization or surgical disconnection of the DAVF. Decisions were needed in 6 patients with cancer about DAVF treatment, modality, aggressiveness, or timing vis a vis other cancer therapies (including conservative management of DAVF in a case in which palliative care was instituted for terminal cancer). Screening identified a previously undiagnosed hypercoagulable state by laboratory testing (in the absence of prior clinical history of thromboembolism or cancer) in 3 cases, and an unsuspected underlying malignancy in 1 case, all of whom required subsequent therapy for these conditions.

\section{Systematic Literature Review}

Our literature search yielded 124 publications with 7 case series, constituting 4 independent cohorts, reporting on the association of cranial DAVF and hypercoagulability (Table 2)..$^{14,15,19,23-25,39}$ One study of 40 patients by van Dijk et al. ${ }^{39}$ did not differentiate spinal from cranial DAVF cases, but we opted to include it because it is a large series. The total number of patients with cranial DAVF was 106 (range 18-40 in the respective cohorts). There was no consistency among the studies on the extent of hypercoagulability workup. In the reported cohorts, the prevalence of abnormal findings suggesting a hypercoagulable state ranged from $15 \%$ to $94 \%$. All the series of cranial DAVFs supported an association with a hypercoagulable state, but not all included a specific assessment of the prevalence of clinical thromboembolism, and none surveyed a potential association with cancer. None of the reported studies addressed the impact of hypercoagulability on clinical management.

\section{Discussion}

DAVFs are relatively rare, with a low detection rate compared with other intracranial vascular malformations. ${ }^{2}$ Yet, DAVFs can lead to significant morbidity and mortality secondary to hemorrhagic events and/or encephalopathy related to leptomeningeal venous drainage.,28 DAVFs are direct artery-to-venous-sinus shunts within the dural leaflet that are believed to develop in adulthood, often in the setting of acquired dural sinus occlusion. ${ }^{5,6,38}$ DAVF development seems to differ in pediatric populations, where high-flow arteriovenous fistulas are associated with congenital venous anomalies, or failure of regression, of the developing venous system. ${ }^{9}$ While the etiology is still controversial and not fully understood, the genesis of these fistulas is likely multifactorial and related to poorly understood interactions of venous hypertension and venous sinus thrombosis. ${ }^{16,26,27,32}$

Previous studies examined laboratory evidence of sys-

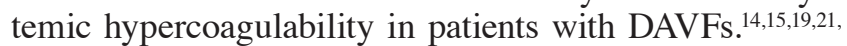
23-25,39 These studies included a broad variability in what coagulation factors were assessed, with several studies addressing a single or limited laboratory marker, and most of the case series did not systematically screen or report clinical manifestations of hypercoagulability. These inconsistences would be expected to result in a reporting bias, underestimating the prevalence of hypercoagulability. None of the previous reports examined the association of malignancy, a known cause of hypercoagulability. Factor V Leiden mutation, leading to a resistance to activated protein $C$, was one of the most reported and studied hypercoagulability factors in DAVFs. After the study by van Dijk et al., ${ }^{39} 2$ other case series studied this association. ${ }^{14,19}$ Gerlach et al. showed a variety of thrombophilic abnormalities in patients with DAVFs, including factor $\mathrm{V}$ Leiden and prothombin G20210A mutations. ${ }^{15}$ The second study, by Izumi et al. ${ }^{19}$ did not assess for the presence of these mutations but did report an abnormal D-dimer level in 16 of 18 patients, with levels above those in a control cohort. In our study, we broadened the definition of hypercoagulability to also include a more comprehensive panel of laboratory tests, and malignancy or a manifestation of systemic thromboembolism.

In our series, 15 of the 17 patients were positive by 1 
or more of these criteria, with the remaining 2 not manifesting clinical factors and not completing laboratory testing. Eight (47\%) of the 17 cases, or $8(80 \%)$ of 10 in which laboratory tests were done, had positive laboratory markers, and $8(47 \%)$ of the 17 had a clinical history of thromboembolism. ${ }^{39}$ Six (35\%) of the 17 patients had an associated malignancy, including 1 patient who was found to harbor a malignancy after investigation regarding hypercoagulability. Eight patients had more than 1 marker of a hypercoagulable state. The prevalence of a positive laboratory test of a hypercoagulable state in the general population has been reported to range from $0.02 \%$ to $7 \%$ depending on the factor tested. ${ }^{11}$ One study reported only 1 of 33 cases (3\% prevalence) with a history of clinical thromboembolism among controls age- and sex-matched to DAVF cases. ${ }^{39}$ All published DAVF series that examined a comparison with a control group confirmed a statistically significant greater prevalence of the respective tested parameters in DAVF cases. . $^{14,15,19,23-25,39}$ The prevalence of any type or stage of cancer is estimated at around 5\% in the general population, $10 \%$ in those above 45 years of age, and $20 \%$ in those above 65 years of age (https://www. cancer.gov/about-cancer/understanding/statistics, https:// www.cancer.org/research/cancer-facts-statistics/survivorfacts-figures.html, https://www.census.gov/content/dam/ Census/library/publications/2015/demo/p25-1143.pdf). Based on the aforementioned data, the prevalence of a hypercoagulable state in patients with DAVFs is well above that of the general population in each of the categories.

A previous study ${ }^{39}$ had opined against regular screening of patients with DAVFs for factor V Leiden and factor II G20210A mutations. This recommendation was attributed to the absence of these mutations in the majority of cases with DAVFs. We note that the study included both cranial and spinal DAVFs, and did not examine cranial lesions separately, nor did it consider hypercoagulable factors other than factor V Leiden and factor II G20210A. Nevertheless, this same study also documented a 5-fold greater prevalence of a history of clinical thromboembolic events among cases with DAVFs compared with age- and sex-matched controls. Based on our results, we advocate a wider workup of hypercoagulability for patients with DAVFs to include the aforementioned list of laboratory hypercoagulability markers, and a thorough review of a history of DVTs, PEs, and cancer, including potential screening for these conditions. Positive findings might influence clinical care, including the need for long-term anticoagulation. This would also influence the treatment modality for DAVFs, pursuing more aggressively a complete obliteration or disconnection of leptomeningeal venous drainage prior to therapeutic anticoagulation, as these features can predispose to catastrophic hemorrhage. ${ }^{33}$

We cannot comment on the association of a hypercoagulable state in spinal DAVF cases, which were outside the scope of our study. Spinal DAVFs are fundamentally different pathologies, where perimedullary venous drainage causes myelopathy but rarely hemorrhage, in contrast to leptomeningeal venous drainage from cranial DAVFs. In fact, a report ${ }^{21}$ examining hypercoagulability in spinal DAVFs specifically did not identify a high association. Pediatric cases were also excluded from our study, as these are believed to arise largely from congenital rather than acquired venous occlusion. ${ }^{20,31,37}$

Our results should be interpreted with caution. As with other case series of DAVFs, the retrospective nature of the study along with the small sample size are major limitations. It was not possible to correlate hypercoagulable state with disease features or severity due to the sample size and missing workup on some of the patients. Not all patients had the full panel of laboratory workup, making it hard to assess the prevalence of individual hypercoagulable factors. However, one would expect that the incomplete assessment in our series (and the published literature) would actually underestimate the true prevalence of associated hypercoagulability. Another limitation of this study is that the majority of the patients referred to our neurovascular team had a symptomatic presentation. The fact that asymptomatic DAVFs are not well represented in the cohort is a limitation against generalizability of our findings to less symptomatic cases. Furthermore, the small sample size of patients did not allow us to conduct meaningful analysis on whether mode of presentation impacts the hypercoagulability association.

It is possible that hypercoagulability was an acutephase reaction to brain hemorrhage or the DAVF itself. And laboratory or clinical evidence of hypercoagulability do not imply lifelong risk, particularly with treatment of malignancy, recovery from ICH, or treatment of the DAVF. Regardless of the causality and mechanistic link between DAVFs and hypercoagulability, the high association necessitates consideration of this phenomenon and integrating it in patient care decisions. Referral bias may have somehow selected cases to our team, with greater likelihood of hypercoagulability or malignancy. Such bias was mitigated by including all consecutive cases presenting to a specialized neurovascular team. We note that none of the cases were referred for DAVF diagnosis because of hypercoagulability as a primary problem, and only 1 case was referred through the oncology service. More likely, the higher prevalence of a hypercoagulable state in our series most likely reflects the broader definition that included clinical states, and the more comprehensive laboratory screening. During more than 2 decades of experience with hundreds of cases by the 2 senior authors, we had also failed to glean more than anecdotal associations until we embarked on the systematic study reported here.

The lack of a control group is another limitation, but the prevalence of hypercoagulability and malignancy in the general population is known, as addressed previously. By any measure, the staggeringly high rate of hypercoagulability or malignancy was clinically relevant and impacted management. Our study results, in conjunction with previous reports, support a recommendation that patients with cranial DAVFs need expanded hypercoagulability and cancer evaluation.

\section{Conclusions}

We have demonstrated a strong association of DAVFs and a hypercoagulable state, including malignancy. Thus, in the setting of a DAVF, both clinical and laboratory in- 
vestigations might be required to uncover an underlying abnormality that could influence clinical management.

\section{References}

1. Aboian MS, Daniels DJ, Rammos SK, Pozzati E, Lanzino G: The putative role of the venous system in the genesis of vascular malformations. Neurosurg Focus 27(5):E9, 2009

2. Al-Shahi R, Bhattacharya JJ, Currie DG, Papanastassiou V, Ritchie V, Roberts RC, et al: Prospective, population-based detection of intracranial vascular malformations in adults: the Scottish Intracranial Vascular Malformation Study (SIVMS). Stroke 34:1163-1169, 2003

3. Awad IA, Little JR, Akarawi WP, Ahl J: Intracranial dural arteriovenous malformations: factors predisposing to an aggressive neurological course. J Neurosurg 72:839-850, 1990

4. Bitoh S, Hasegawa H, Fujiwara M, Nakata M: Traumatic arteriovenous fistula between the middle meningeal artery and cortical vein. Surg Neurol 14:355-358, 1980

5. Borden JA, Wu JK, Shucart WA: A proposed classification for spinal and cranial dural arteriovenous fistulous malformations and implications for treatment. J Neurosurg 82:166179, 1995

6. Chaichana KL, Coon AL, Tamargo RJ, Huang J: Dural arteriovenous fistulas: epidemiology and clinical presentation. Neurosurg Clin N Am 23:7-13, 2012

7. Chaudhary MY, Sachdev VP, Cho SH, Weitzner I Jr, Puljic S, Huang YP: Dural arteriovenous malformation of the major venous sinuses: an acquired lesion. AJNR Am J Neuroradiol 3:13-19, 1982

8. Chung SJ, Kim JS, Kim JC, Lee SK, Kwon SU, Lee MC, et al: Intracranial dural arteriovenous fistulas: analysis of 60 patients. Cerebrovasc Dis 13:79-88, 2002

9. Davies MA, TerBrugge K, Willinsky R, Coyne T, Saleh J, Wallace MC: The validity of classification for the clinical presentation of intracranial dural arteriovenous fistulas. J Neurosurg 85:830-837, 1996

10. Deitcher SR: Disease management. Hypercoagulable states. Cleveland Clinic Center for Continuing Medical Education. (http://www.clevelandclinicmeded.com/medicalpubs/ diseasemanagement/hematology-oncology/hypercoagulablestates/) [Accessed July 27, 2017]

11. Deitcher SR, Gomes MP: Hypercoagulable state testing and malignancy screening following venous thromboembolic events. Vasc Med 8:33-46, 2003

12. Freckmann N, Sartor K, Herrmann HD: Traumatic arteriovenous fistulae of the middle meningeal artery and neighbouring veins or dural sinuses. Acta Neurochir (Wien) 55:273281,1981

13. Gandhi D, Chen J, Pearl M, Huang J, Gemmete JJ, Kathuria $S$ : Intracranial dural arteriovenous fistulas: classification, imaging findings, and treatment. AJNR Am J Neuroradiol 33:1007-1013, 2012

14. Gerlach R, Boehm-Weigert M, Berkefeld J, Duis J, Raabe A, Seifert V, et al: Thrombophilic risk factors in patients with cranial and spinal dural arteriovenous fistulae. Neurosurgery 63:693-699, 2008

15. Gerlach R, Yahya H, Rohde S, Böhm M, Berkefeld J, Scharrer I, et al: Increased incidence of thrombophilic abnormalities in patients with cranial dural arteriovenous fistulae. Neurol Res 25:745-748, 2003

16. Hamada $\mathrm{Y}$, Goto K, Inoue T, Iwaki T, Matsuno H, Suzuki S, et al: Histopathological aspects of dural arteriovenous fistulas in the transverse-sigmoid sinus region in nine patients. Neurosurgery 40:452-458, 1997

17. Houser OW, Baker HL Jr, Rhoton AL Jr, Okazaki H: Intracranial dural arteriovenous malformations. Radiology 105:55-64, 1972

18. Inoue T, Nishimura S, Hayashi N, Numagami Y, Tomita T,
Nishijima M: Cavernous sinus dural arteriovenous fistula associated with the development of sphenoidal ridge meningioma-case report. Neurol Med Chir (Tokyo) 47:317-321, 2007

19. Izumi T, Miyachi S, Hattori K, Iizuka H, Nakane Y, Yoshida $\mathrm{J}$ : Thrombophilic abnormalities among patients with cranial dural arteriovenous fistulas. Neurosurgery 61:262-269, 2007

20. Jafar JJ, Awad IA, Huang PP: Intracranial vascular malformations: clinical decisions and multimodality management strategies, in Jafar JJ, Awad IA, Rosenwasser RH (eds): Vascular Malformations of the Central Nervous System. Philadelphia: Lippincott Williams \& Wilkins, 1999

21. Jellema K, Tijssen CC, Fijnheer R, de Groot PG, Koudstaal PJ, van Gijn J: Spinal dural arteriovenous fistulas are not associated with prothrombotic factors. Stroke 35:2069-2071, 2004

22. Khogeer H, Alfattani A, Al Kaff M, Al Shehri T, Khojah O, Owaidah T: Antiphosphatidylserine antibodies as diagnostic indicators of antiphospholipid syndrome. Lupus 24:186-190, 2015

23. Kraus JA, Stüper BK, Berlit P: Association of resistance to activated protein $\mathrm{C}$ and dural arteriovenous fistulas. J Neurol 245:731-733, 1998

24. Kraus JA, Stüper BK, Müller J, Nahser HC, Klockgether T, Berlit P, et al: Molecular analysis of thrombophilic risk factors in patients with dural arteriovenous fistulas. J Neurol 249:680-682, 2002

25. Kraus JA, Stüper BK, Nahser HC, Klockgether T, Berlit P: Significantly increased prevalence of factor V Leiden in patients with dural arteriovenous fistulas. J Neurol 247:521523,2000

26. Kwon BJ, Han MH, Kang HS, Chang KH: MR imaging findings of intracranial dural arteriovenous fistulas: relations with venous drainage patterns. AJNR Am J Neuroradiol 26:2500-2507, 2005

27. Lalwani AK, Dowd CF, Halbach VV: Grading venous restrictive disease in patients with dural arteriovenous fistulas of the transverse/sigmoid sinus. J Neurosurg 79:11-15, 1993

28. Lasjaunias P, Chiu M, ter Brugge K, Tolia A, Hurth M, Bernstein M: Neurological manifestations of intracranial dural arteriovenous malformations. J Neurosurg 64:724-730, 1986

29. Lee SK, Hetts SW, Halbach V, terBrugge K, Ansari SA, Albani B, et al: Standard and guidelines: intracranial dural arteriovenous shunts. J Neurointerv Surg 9:516-523, 2017

30. Mironov A: Pathogenetical consideration of spontaneous dural arteriovenous fistulas (DAVFs). Acta Neurochir (Wien) 131:45-58, 1994

31. Morita A, Meyer FB, Nichols DA, Patterson MC: Childhood dural arteriovenous fistulae of the posterior dural sinuses: three case reports and literature review. Neurosurgery 37:1193-1200, 1995

32. Mullan S: Reflections upon the nature and management of intracranial and intraspinal vascular malformations and fistulae. J Neurosurg 80:606-616, 1994

33. Peng T, Liu A, Jia J, Jiang C, Li Y, Wu Z, et al: Risk factors for dural arteriovenous fistula intracranial hemorrhage. J Clin Neurosci 21:769-772, 2014

34. Pierot L, Chiras J, Duyckaerts C, Jason M, Martin N: Intracranial dural arteriovenous fistulas and sinus thrombosis. Report of five cases. J Neuroradiol 20:9-18, 1993

35. Safavi-Abbasi S, Di Rocco F, Nakaji P, Feigl GC, Gharabaghi A, Samii M, et al: Thrombophilia due to Factor V and Factor II mutations and formation of a dural arteriovenous fistula: case report and review of a rare entity. Skull Base 18:135143,2008

36. Sakurai N, Koike Y, Hashizume Y, Takahashi A: Dural arteriovenous malformation and sinus thromboses in a patient 
with prostate cancer: an autopsy case. Intern Med 31:10321037, 1992

37. Souza MP, Willinsky RA, terBrugge KG: Intracranial dural arteriovenous shunts in children. The Toronto experience. Interv Neuroradiol 9 (Suppl 2):47-52, 2003

38. Terada T, Higashida RT, Halbach VV, Dowd CF, Tsuura M, Komai N, et al: Development of acquired arteriovenous fistulas in rats due to venous hypertension. J Neurosurg 80:884-889, 1994

39. van Dijk JM, TerBrugge KG, Van der Meer FJ, Wallace MC, Rosendaal FR: Thrombophilic factors and the formation of dural arteriovenous fistulas. J Neurosurg 107:56-59, 2007

40. Wang SS, Li CH, Zhang XJ, Wang RM: Investigation of the mechanism of dural arteriovenous fistula formation induced by high intracranial venous pressure in a rabbit model. BMC Neurosci 15:101, 2014

\section{Disclosures}

The authors report no conflict of interest concerning the materi- als or methods used in this study or the findings specified in this paper.

\section{Author Contributions}

Conception and design: all authors. Acquisition of data: Awad, Polster, Zeineddine, Lee. Analysis and interpretation of data: all authors. Drafting the article: all authors. Critically revising the article: all authors. Reviewed submitted version of manuscript: all authors. Approved the final version of the manuscript on behalf of all authors: Awad. Study supervision: Awad.

\section{Supplemental Information}

\section{Previous Presentations}

Portions of the data were accepted for poster presentation at the 85th AANS annual scientific meeting, in Los Angeles, California, April 22-26, 2017.

\section{Correspondence}

Issam A. Awad, Section of Neurosurgery, University of Chicago Medicine, 5841 S Maryland Ave, MC3026/Neurosurgery J341, Chicago, IL 60637. email: iawad@uchicago.edu. 